\title{
The study of stability, combustion characteristics and performance of water in diesel emulsion fuel
}

\author{
Zulkifli Syafiq ${ }^{1}$, Othman Fahmi ${ }^{1}$, Omar. I Awad ${ }^{1}$ and Abdullah Adam ${ }^{1,2, *}$ \\ ${ }^{1}$ Faculty of Mechanical Engineering, Universiti Malaysia Pahang, 26600 Pekan, Pahang, Malaysia \\ ${ }^{2}$ Automotive Engineering Center, Universiti Malaysia Pahang, 26600 Pekan, Pahang, Malaysia
}

\begin{abstract}
A single cylinder diesel engine study of water in diesel emulsions was conducted to investigate the stability effect of emulsion fuel on three different fuel blends and the water emulsification effect on the engine performance. Emulsified fuels contained $2 \%$ of surfactant including Span 80 Tween 80 and tested 10 HLB number. The blends also varied of $5 \%, 10 \%$ and $15 \%$ of water in diesel ratios namely as BSW5, BSW 10 and BSW15. The fuel blends performance was tested using a single cylinder, direct injection diesel engine, operating at $1860 \mathrm{rpm}$. The results on stability reveal that high shear homogenizer yields more stability on emulsion fuel than mechanical stirrer and ultrasonic water bath. The engine performance results show that the ignition delay and peak pressure increase with the increment of water percentage up to $15 \%$. However, the results indicate the increment of water percentage is also shows a significant decrease in engine power.
\end{abstract}

\section{Introduction}

Limitations of fossil fuel resources and restrictions on environmental pollution have directed research programs worldwide to introduce the new method that not only ensures rationalization of fuel consumption but also keep emissions at low levels from different combustion devices. Particular attention is indeed given to both petrol and diesel engines as they represent a significant contributor to both fuel consumption and environmental pollution. As the demand for fossil fuel increase, there is a concern for the effect of burnt fossil fuel that will pollute the environment. Alternative fuels including biodiesels as well as the use of fuel additives are among recent methodologies that aim at reducing the utilization of fuels and/or improving engine performance while meeting environmental regulations. The mixing of water-fuels emulsions is considered as promising ways to realize improved fuel economics and usage of fuels. The technology of water fuel emulsion has been stated as the most universal and effective method that enable simultaneous reduction of the engine smoke level and nitrogen oxides $\left(\mathrm{NO}_{\mathrm{X}}\right)$ without the necessity for engine modifications [1].

* Corresponding author: adam@ump.edu.my 
The interest in water-in-diesel emulsions derives from the fact that water in the form of micrometer-sized droplets exerts some positive effects on the combustion of the fuel. The main reason for a stronger interest in incorporating water in diesel than in gasoline is that the high combustion temperature and the high pressure that exist in diesel engines is particularly suitable for the concept. An experimental on water addition emulsified droplet combustion reveal the combination of high-pressure environment and a high boiling temperature fuel is emphasis on improving smoke reduction. Therefore, water-oil emulsions are particularly suitable for applications in diesel engines, where high-pressure combustion exists, a relatively non-volatile fuel is used, and smoke emission problem exists [2]. In addition, using emulsion diesel can lead to other advantages such as additional momentum in jet behavior which may assist better mixing of fuel and air. Moreover, the presence of tiny water particles may lead to micro explosion, which also enhance further fuel atomization [3]. Use of diesel emulsions has been shown to give several interesting effects, such as (i) reduced NOx emission, lower soot and particulate contents in the exhaust, and (ii) improved combustion efficiency [4-6].

Emulsion stability study is to measure the separation time for water and fuel. Research about emulsion stability reveals that emulsion instability leads to changes of emulsion properties [7-9]. This is the major challenge to prepare emulsion itself. The first challenge depends on the emulsion preparation method or the technology used to deform the dispersed phase into fine droplets, while the second is solved or retarded by the proper selection of the type and concentration of emulsifier to reduce the interfacial tension between two immiscible liquids.

The proper preparation method is needed to verify the efficiency the water fuel emulsion including the mixer/blender types and the surfactant's HLB number. Gouvêa et al. found that the chemical reaction rates can be enhanced by using ultrasonic technique [10]. The ultrasonic waves are of mechanically vibrating types and propagate through a transmission medium causing cavitation. Side-by-side, the motion of ultrasonic wave creates an alternate positive and negative pressure waves. Both of these methods forms a strong stirring affect and mixes the two immiscible fluids. Therefore, the ultrasonic technique would be used beneficially to prepare water-diesel emulsions [11-14]. The mechanical stirrer machine, the mostly used emulsifying machine, stirs up the mixture of continuous and dispersed phase with the presence of surfactant [15]. With the increase in the stirrer speed, the mean droplet diameter is observed to be reduced almost linearly[16]. In addition, the high shear homogenizer is used to blend the emulsion to ensure the mixture in a homogenous state [17]. It is used to allow optimal mixing and homogenization under higher viscosity and delivers more reduction in droplets size.

Surfactants are compounds that lower the surface tension or interfacial tension between two liquids. Surfactants may act as foaming agents, wetting agents and emulsifier. To increase the kinetic stability, surfactant act as emulsifier needed to stabilize the emulsion. The emulsifier has the ability to dissolve with oil (lipophilic or hydrophobic) and water (hydrophilic) with different degree of solubility expressed by the hydrophilic-lipophilic balance (HLB). HLB value an important to develop emulsification [18, 19]. The most popular emulsifiers used for water-diesel emulsification are those based on aliphatic hydrocarbons as sorbitan esters known as span. While for oil-in-water emulsifications, emulsifiers based on polysorbitan esters known as tween. Researchers reported that the applications of a mixture of span and tween lead to better results [20, 21]. This study is to investigate emulsion with Span 80 Tween 80 and HLB 10. The purpose of the current work is to create emulsified diesel-water fuel with three different type of mixer and study the effect of $5 \%, 10 \%$ and $15 \%$ percentage of water content in water diesel emulsion on diesel engine performance. 


\section{Experimental setup}

Table 1 shows the commercial non-ionic surfactants Span 80 (hydrophobic) and Tween 80 (hydrophilic) adopted in this work as they were expected to stabilize emulsions effectively. The formula for blend Span 80 and Tween 80 to any given HLB value shown in equation 1 and 2.

$$
\begin{gathered}
\%(A)=\left(H L B-H L B_{B}\right) \times 100 / H L B_{A}-H L B_{B} \\
\%(B)=100-\%(A)
\end{gathered}
$$

Table 1. Physicochemical properties of surfactants.

\begin{tabular}{|lr|c|c|}
\hline \multicolumn{2}{|c|}{ Properties } & Span80 & Tween80 \\
\hline Density & $\mathrm{kg} / \mathrm{m}$ & 994 & 1060 \\
\hline Molar mass & $\mathrm{g} / \mathrm{mol}$ & 428.6 & 1310 \\
\hline Hydroxyl value & $\mathrm{mgKOH} / \mathrm{g}$ & $193-210$ & $65-80$ \\
\hline HLB value & - & 4.3 & 15.0 \\
\hline Content in 10 HLB (\%) & - & 46.7 & 53.3 \\
\hline
\end{tabular}

To stabilize the emulsions, $2 \%$ by volume surfactant mixture consisting of Span 80 and Tween 80 (HLB 10) were blended by a mechanical stirrer, ultrasonic water bath machine (FB15051 Fisherbrand) and high shear homogenizer. The mixer were all set to operate for 10 minutes to make sure there are no impurities to achieve the maximum homogenization. Then the emulsified fuel was kept in $100 \mathrm{ml}$ lab container and observation been done to measure the emulsion stability of the fuel in the room temperature.

The engine used in this experiment was the YANMAR TF120M single cylinder, four strokes with water cooled diesel engine. The engine specifications are listed in Table 4. A schematic diagram of the experimental setup is shown in Figure 1. The engine is equipped with two fuel tanks, air intake system and data acquisition system. The engine works at a constant speed of $1860 \mathrm{rpm}$. Three blends emulsion fuel with water content of 5\%,10\% and $15 \%$ (namely, BSW5, BSW10, and BSW15) were used in this experiment. The engine was set at $0 \%, 25 \%, 50 \%, 75 \%$ and $100 \%$ engine load at injection angle $18^{0} \mathrm{BTDC}$. The engine was tested repeatedly prior to actual testing in order to ensure all instruments are in the stable condition and the engine testing was done according to the SAE J1349 standard.

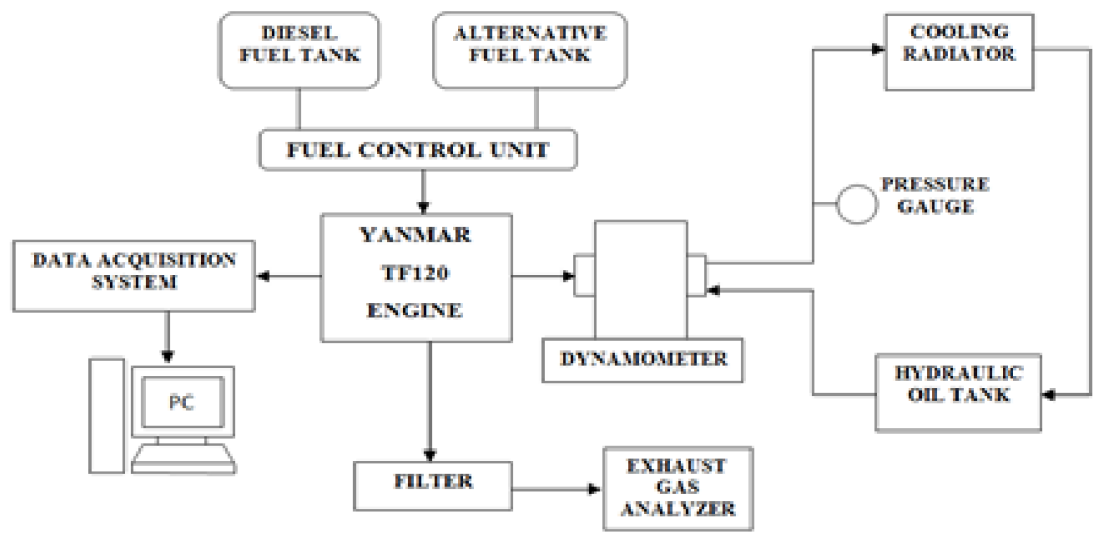

Fig. 1. Schematic diagram of engine testing. 
Table 2. Engine specification.

\begin{tabular}{|c|c|}
\hline Description & Specification \\
\hline Engine model & YANMAR TF120M \\
\hline Engine type & $\begin{array}{c}\text { Single cylinder, horizontal, } \\
\text { diesel } 4 \text { stroke cycle }\end{array}$ \\
\hline Combustion system & direct injection \\
\hline Number of cylinders & 1 \\
\hline Bore x stroke (mm) & $92 \times 96$ \\
\hline Displacement (L) & 0.638 \\
\hline Injection timing & $18^{\circ}$ BTDC \\
\hline Compression ratio & 17.7 \\
\hline Continuous output (HP) & $10.5 \mathrm{HP}$ at $2400 \mathrm{rpm}$ \\
\hline Rated output (HP) & $12 \mathrm{HP}$ at $2400 \mathrm{rpm}$ \\
\hline
\end{tabular}

\section{Results and discussion}

The effect of emulsion stability on the three different mixers including mechanical stirrer, ultrasonic water bath and high shear homogenizer were shown in Figure 2, 3 and 4 respectively. Emulsion stability is the capability of an emulsion to conserve the emulsifying layer after being kept motionless or heated constant temperature at a preset time. In overall, the effect of water addition in the form of emulsion fuel reveals that the increasing separation length of the emulsion fuel. The ultrasonic water bath shows the emulsion produced is the fastest to conserve the emulsifying layer than mechanical stirrer and high shear homogenizer. The faster time taken of separation of water from emulsion show the ultra-sonication is significantly not in a homogenized state. The separation length of the emulsion produced by the mechanical stirrer and high shear homogenizer show similar value, but emulsion of high shear homogenizer take longer time to be in a stable state. It is due to the principle of the mixer of the high shear homogenizer that able to subdivision of particles into subtle sizes to create an emulsion [22].

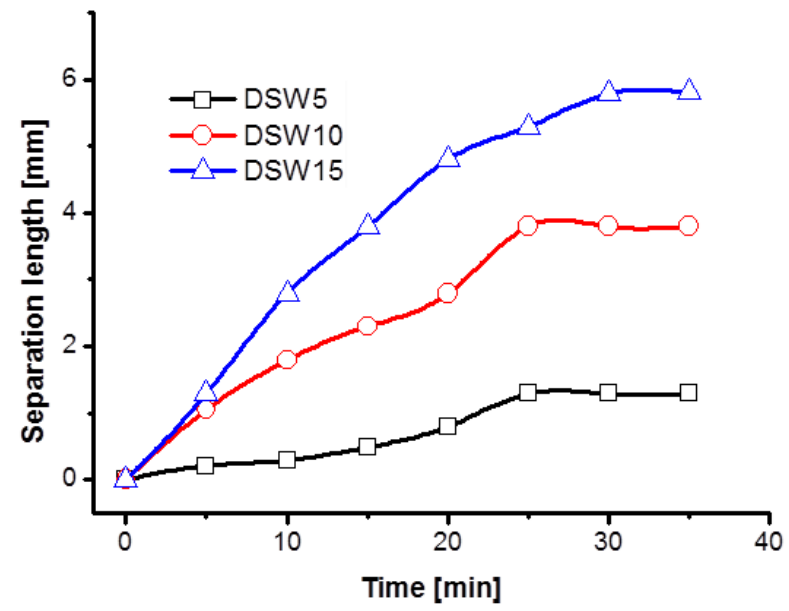

Fig. 2. Separation rate of emulsified fuel using mechanical stirrer. 


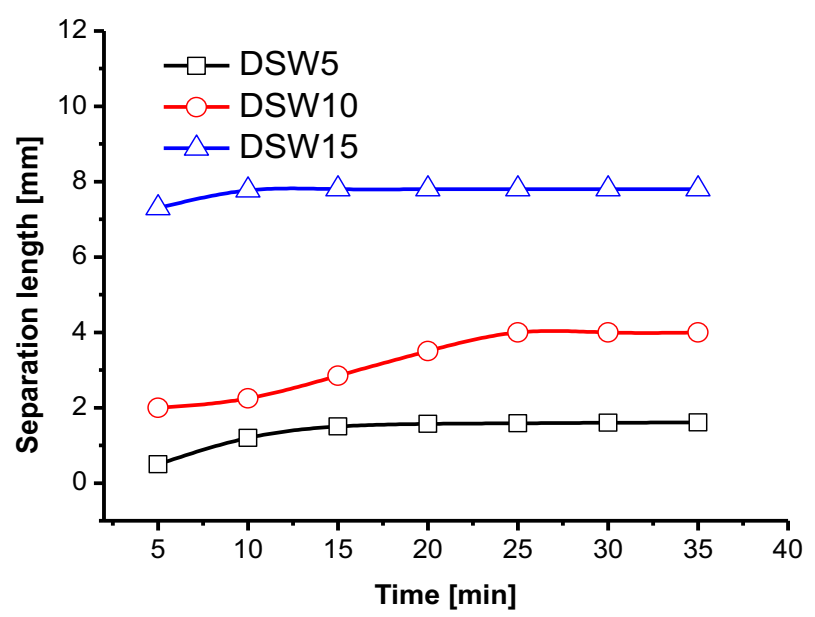

Fig. 3. Separation rate of emulsified fuel using ultrasonic water bath.

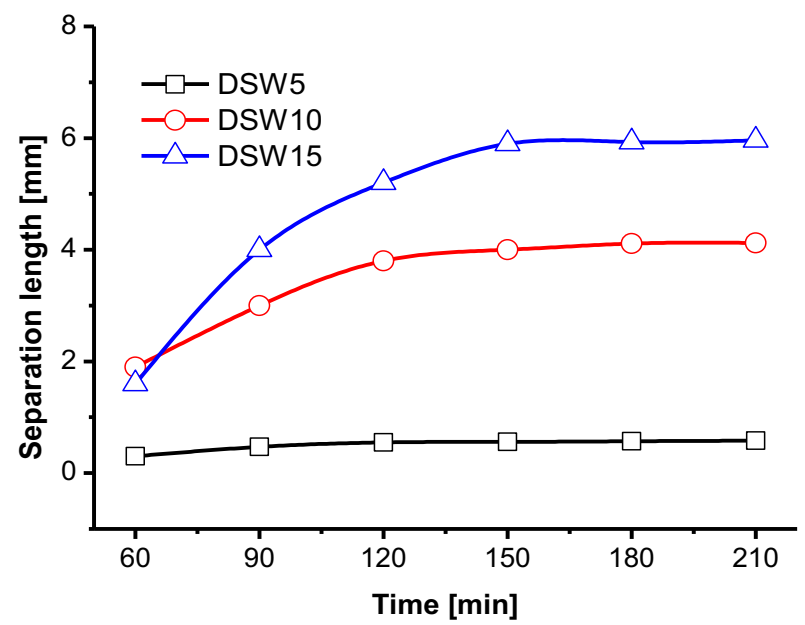

Fig. 4. Separation rate of emulsified fuel using high shear homogenizer.

The effect of the emulsion on the power curve has been illustrated in Figure 5. It is observed that with the increase in load condition, the power slightly increases for the three blended emulsions. The average power curve decreases when the increase the addition water in emulsion fuel. This is because of water in emulsion influence combustion of the fuel. However, at $100 \%$ engine load, the power increases as the water in emulsion increase. This is due to the engine reached the limit so that the speed will change (slow down) or a lower gear will be used to multiply the engine torque by a greater factor (and consequently cause the engine speed to increase).

Figure 6 shows the effect addition of water in emulsion to the location of the peak pressure in unit CAD. As, expected, the crank angle degree increase as increase the water content in emulsion. This is due to the effect of ignition delay to start of the combustion. By increasing the water content in emulsion, the vaporization of water in emulsion increase and increase the compression ratio of the engine then affect the peak pressure of in the engine. 


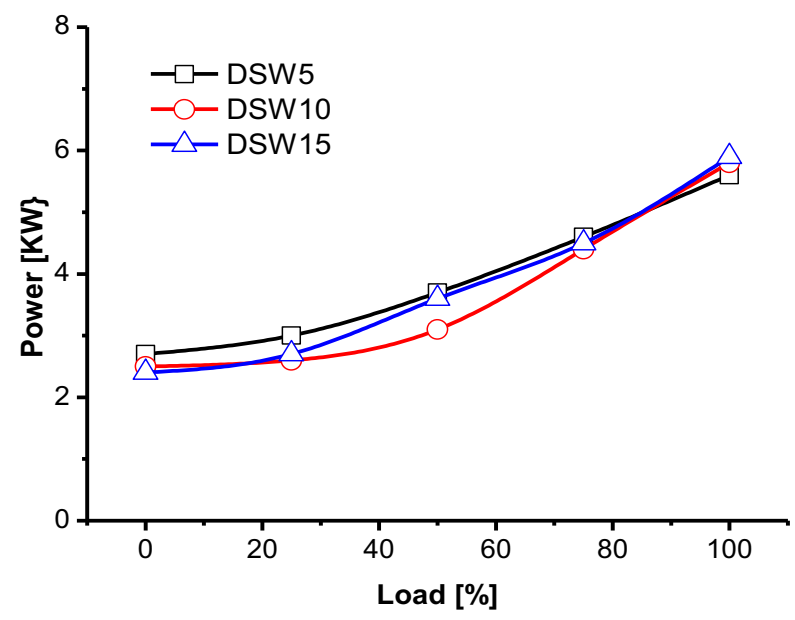

Fig. 5. Engine power curve of different blend concentration.

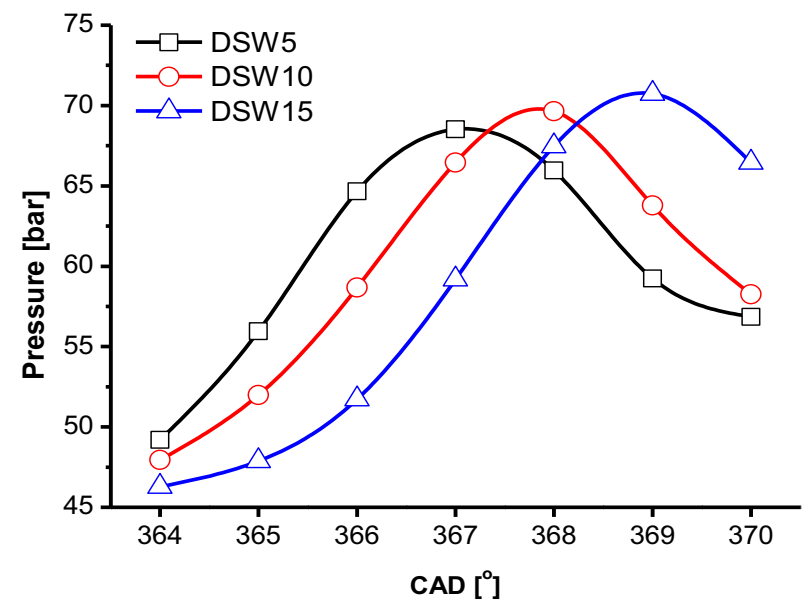

Fig. 6. Combustion peak pressure of various emulsion blends.

Ignition pressure is the start of ignition point at which the pressure increases suddenly from the graph pressure-crank angle degree. Ignition delay is defined as the period from when the start of injection (SOI) to the start of combustion (SOC). So, the ignition delay angle is the difference between the two angles in degree. The variation of the pressure with crank angle degree (CAD) for different emulsion is shown in Figure 7. It is clear that as the percentage of water in emulsion increase, the ignition delay increase. It is due to the heat absorption by water vaporization in the fuel jet. The ignition delay period is when the fuel that has been injected into the cylinder is undergoing chemical and physical preparation for combustion. Thus, by adding water into emulsion fuel, it requires less compression (negative) work due to the longer ignition delay during the compression stroke [23]. 

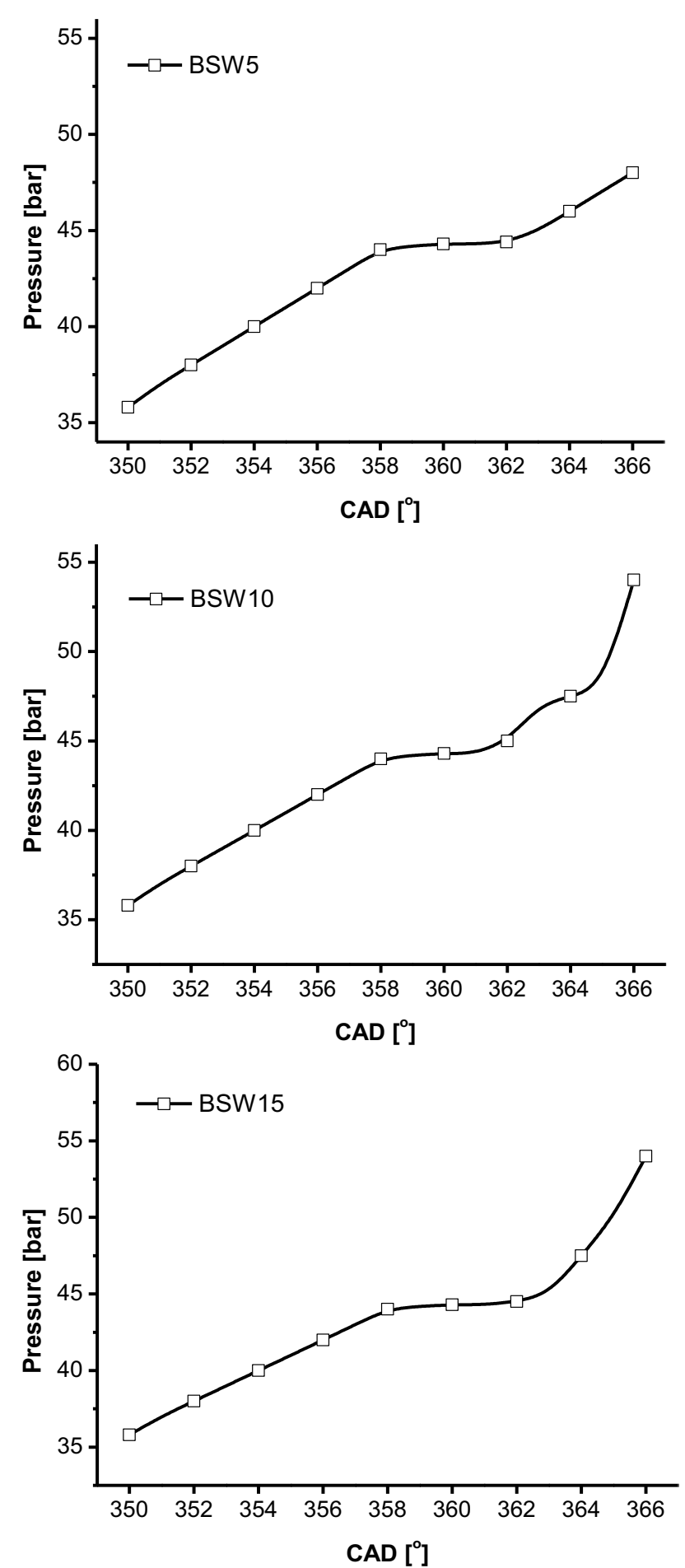

Fig. 7. Comparison of ignition delay of various emulsion blends. 


\section{Conclusions}

The research project summaries the specific issues related to emulsion preparation, the types of emulsifying agents or surfactants and the HLB value. In this paper, an attempt has been made to choose the optimum mixer to blend the water-diesel by adding surfactant. By measuring the emulsion stability, the high shear homogenizer produce the optimum homogenous state for the emulsion compared to the mechanical stirrer and ultrasonic water bath. The applications of emulsified fuel, in the form of water-diesel have found to have influenced the engine combustion. Water-diesel emulsions added by surfactant Span 80 Tween 80 (HLB 10) were tested on diesel engine. The comparisons were made in different water content $(5 \%, 10 \%$ and $15 \%)$ of emulsion. It may conclude that the addition of water up to $15 \%$ in the form of emulsion improves the combustion efficiency of the diesel engine. Addition the water, the ignition delay and peak pressure increase. However, the power curve decreases when increasing the water content.

Malaysian Ministry of Higher Education and Universiti Malaysia Pahang is greatly acknowledged for the technical and financial supports under RAGS grant (RDU121418).

\section{References}

1. A. M. Attia, A. Kulchitskiy, Fuel, 116, 703 (2014)

2. D. Cook, C. Law, Comb. Sci. \& Tech., 18, 217 (1978)

3. O. Armas, R. Ballesteros, F. J. Martos, J. R. Agudelo, Fuel, 84, 1011 (2005)

4. M. E. A. Fahd, Y. Wenming, P. Lee, S. Chou, C. R. Yap, Appl. Enrg., 102, 1042 (2013)

5. P. Janulis, Rnwble. Enrg., 29, 861 (2004)

6. M. Abu-Zaid, Enrg. Conv. \& Mgmt., 45, 697 (2004)

7. H. Schubert, R. Engel, Che. Eng. R\&D, 82, 1137 (2004)

8. Y. Xie, J. Chen, S. Zhang, K. Fan, G. Chen, Z. Zhuang, M. Zeng, D. Chen, L. Lu, L. Yang, Int. J. of Pharm., 500, 110 (2016)

9. X. Zhang, J.-y. Wu, J. Niu, Solar Enrg. Mat. \& Solar Cells, 147, 211 (2016)

10. D. P. Gouvêa, V. D. Bareño, J. Bosenbecker, B. B. Drawanz, P. D. Neuenfeldt, G. M. Siqueira, W. Cunico, Ultrasncs. Sonoche., 19, 1127 (2012)

11. X. Liu, J. Wu, J. of Acoust. Soc. America, 125, 1319 (2009)

12. W. Lauterborn, C.-D. Ohl, Ultrasncs. Sonoche., 4, 65 (1997)

13. A. Tezel, S. Mitragotri, Biophy.J., 85, 3502 (2003)

14. L. Wolloch, J. Kost, J. of Controlled R., 148, 204 (2010)

15. C.-Y. Lin, K.-H. Wang, Fuel, 82, 1367 (2003)

16. B. K. Debnath, U. K. Saha, N. Sahoo, Rnwble. \& Stnble. Enrg. Rvws., 42, 196 (2015)

17. S. M. Kumar, A. Kerihuel, J. Bellettre, M. Tazerout, P. of Int. of Mech. Eng., 219, 583 (2005)

18. C. P. Fernandes, M. P. Mascarenhas, F. M. Zibetti, B. G. Lima, R. P. Oliveira, L. Rocha, D. Q. Falcão, R. B. F., 23, 108 (2013)

19. X. Jin, D. A. Streett, C. A. Dunlap, M. E. Lyn, Bio. Cntrl., 46, 226 (2008)

20. A. Lif, K. Holmberg, Adv. in Clld. \& Int. Sc., 123, 231 (2006)

21. Z. Fu, M. Liu, J. Xu, Q. Wang, Z. Fan, Fuel, 89, 2838 (2010)

22. J. Taghinia, M. Rahman, K. Tim, T. Siikonen, Che. Eng. R\&D, 106, 327 (2016)

23. N. Samec, B. Kegl, and R.W. Dibble, Fuel, 81, 2035 (2002) 